\title{
ESTRATÉGIAS QUILOMBOLAS: SEGMENTARIDADE E DISSENSO NA POLÍTICA ÉTNICA MARANHENSE
}

\author{
Igor Thiago Silva de Sousa ${ }^{1}$
}

\section{RESUMO}

Este trabalho tem como objetivo analisar as formas de garantia de direitos territoriais às chamadas "comunidades remanescentes de quilombos" no Maranhão através de seus segmentos organizados. Como primeiro segmento temos a ACONERUQ (Associação das Comunidades Negras Rurais Quilombolas), que surge em 1997, funcionando como um "fórum de representação das comunidades quilombolas". Por sua vez, os caminhos políticos e estratégias de intervenção na garantia de direitos territoriais não são unitários, apresentando-se de forma multifacetada e sob diferentes visões sobre os caminhos de interface frente o Estado, o que coloca em questão a unidade política da desta entidade e culmina com a eclosão do MOQUIBOM (Movimento Quilombola do Maranhão) em meados de 2010, apontando divergências nas formas de ação política dos quilombolas. Estes polos organizados têm entre si estratégias diferenciadas e certos antagonismos públicos, o que coloca em pauta as percepções políticas das organizações quilombolas, que politizam seus laços comunitários e práticas a partir de entendimentos, formas de mobilização e parcerias políticas diferentes entre si.

Palavras-chave: comunidades quilombolas, direitos territoriais, grupos étnicos, movimentos sociais, Maranhão.

\section{QUILOMBOLAS STRATEGIES: SEGMENTARITY AND DISSIDENCE IN MARANHÃO ETHNIC POLITICS}

\begin{abstract}
This study aims to examine ways to guarantee land rights to so-called "remaining quilombo communities" in Maranhão through its organized segments. As the first segment we have ACONERUQ (Associação das Comunidades Negras Rurais Quilombolas), which appears in 1997, working as a "representative forum of the Quilombo communities." In turn, the political ways and intervention strategies on territorial rights guarantee are not unitary, presenting a multifaceted way and under different views on the front interface paths the State, which calls into question the political unity of this entity and culminates with the outbreak of MOQUIBOM (Movimento quilombola do Maranhão) in mid-2010, indicating differences in the forms
\end{abstract}

\footnotetext{
${ }^{1}$ Graduado em Ciências Sociais pela Universidade Estadual do Maranhão (UEMA). Mestrado em Antropologia pela Universidade Federal de Santa Catarina (UFSC). Doutorando em Sociologia pela Universidade Federal do Rio Grande do Sul (UFRGS). E-mail: igorthiago.sousa@gmail.com
} 
of political action of the quilombolas. These poles have organized together different strategies and certain public antagonisms, which puts on the agenda the political perceptions of quilombo organizations which politicize their community ties and practices from understandings, forms of mobilization and different political partnerships with each other.

Keywords: ethnic groups, Maranhão, quilombo communities, social movements, territorial rights.

\title{
1. INTRODUÇÃO
}

O trabalho em questão se baseia na análise das ações de dois segmentos organizados do Movimento quilombola no Maranhão. Para isso, foi feita uma revisão bibliográfica, situando a colaboração do Movimento Negro para os processos de organização das comunidades quilombolas no Maranhão e entrevistas com lideranças da ACONERUQ e MOQUIBOM, tendo em vista situar percepções e entendimentos diferenciados. Foi realizado trabalho de campo acompanhando reuniões deliberativas, assembleias e pequenos encontros formativos, tendo em vista perceber desde encontros e processos de deliberações locais, até grandes atos e protestos, percebendo processos de mobilização e reivindicação de direitos.

Para isso, foi necessário perceber as manifestações políticas, como aponta James Scott (2013), em formas não explícitas, em seus meandros, nas formas não declaradas ou óbvias ao observador médio, mas encontrando-se em pequenos atos, formas de solidariedade e construção de meios de assistência mútua.

\begin{abstract}
Em circunstâncias normais, os subordinados têm todo o interesse em evitar qualquer manifestação explícita de insubordinação. Claro que, na prática, também têm o maior interesse em desenvolver formas de resistência - em minimizar as exacções, o trabalho e as humilhações a que são submetidos. A conciliação destes dois objectivos aparentemente antagónicos é normalmente alcançada pela persecução de formas de resistência que, justamente evitam o confronto aberto com as estruturas de autoridade a que se procura resistir (SCOTT, 2013, p. 132).
\end{abstract}

Assim, ao tratar de movimentos e organizações sociais, foi necessário perceber os discursos postos em dois planos (interno e externo), um mais propenso a disputas e desentendimentos entre militantes e outro em que aparentemente há coesão e pautas unitárias. Para tal, tomo como principal estratégia para a análise proposta a "observação situada", proposta pela Antropologia Interpretativa, pois, segundo Geertz (2008), as formas do saber são sempre, e inevitavelmente, locais, inseparáveis de seus instrumentos e invólucros em que para o entendimento das percepções dos agentes políticos das entidades, será necessário para que se torne possível uma "descrição densa".

O primeiro segmento organizado se situa a partir da criação da ACONERUQ (Associação das Comunidades Negras Rurais Quilombolas) ainda na década de 1990; já o segundo, se dá com a criação do MOQUIBOM (Movimento Quilombola do Maranhão) em meados de 2010. Nesse sentido, o norteador do trabalho de campo foi perceber as práticas desses sujeitos, suas ações e as particularidades no acionar de garantias instituídas a partir de direitos conquistados desde a nova Carta Magna. Almejou-se compreender como a partir de diferentes percepções e leituras políticas, 
tanto a ACONERUQ, quanto O MOQUIBOM realizam suas estratégias, situadas dentro de um leque de visões de mundo e observações sobre (im)possibilidades.

Por outro lado, a ideia de um corpo coeso e unitário parece soar vazia, na medida em que certos enquadramentos são por demais rígidos, incapazes de perceber fissuras e as mobilidades existentes dentro desses mesmos segmentos. Assim, é necessário em termos analíticos um descentramento a partir de espaços de incerteza, de pontos intermediários em que se privilegia o acionar dos sujeitos, como pontua Michel Agier (2012). Momentos em que além de identidades fixas, amarras que congelam as análises em pontos mortos e determinados, ganham força a possibilidade de alteração, o colocar-se em movimento, momentos liminares, focando aquilo que se produz e altera a ordem existente.

Para Agier (2012): "este descentramiento es político en el sentido de que privilegia el acionar y el momento de cambio que introduce una modificacion en el orden social dado, generando asi la posibilidad de ver y de comprender el movimiento y el cambio que estan ocurriendo" (AGIER, 2012, p. 11). É importante perceber as friç̧ões, fissuras e a heterogeneidade dentro daquilo que se designou por identidades, frisando aspectos que ressaltam a importância das fronteiras em termos da alteridade. Dessa forma, emerge o conceito de sujeito. Este sujeito, por mais que submetido a um poder, conformado em certos termos, parece não se resignar dentro do que está inserido, não se conter dentro da ordem delimitada e por mais que submetido, "pude, de hecho, sobreactuar o anticipar su rol dando así la impresión de que está coproduciendolo, queriendolo y deseandolo realmente" (AGIER, 2012, p.18). Portanto, na análise dos segmentos organizados que compõem o Movimento Quilombola no Maranhão, frisaram-se esse estar em movimento, os diferentes modos de acionar direitos conquistados, formas de percepção e entendimento que não apenas variam entre diferentes polos, que são compostos pelos mesmos tipos sociais, a saber, os quilombolas, mas também por sujeitos que falam a partir de diferentes experiências e percepções de mundo.

Para situar a exposição, inicialmente se comentará a emergência de cada polo organizativo do Movimento Quilombola, como forma de mapear de maneira genérica a existência de cada segmento organizativo das comunidades quilombolas no Maranhão, para daí situar alguns entendimentos diferenciados entre esses sujeitos que compõem tanto a ACONERUQ quanto o MOQUIBOM. Por fim, se ressaltará uma estratégia política diferenciada do MOQUIBOM, a busca por alianças com diferentes etnias indígenas, quebradeiras de coco babaçu, pescadores arteriais e camponeses, compondo a denominada Teia de Povos e Comunidades Tradicionais.

\section{ESTRATÉGIAS QUILOMBOLAS: O MOQUIBOM, ACONERUQ E AS DIFERENTES LEITURAS POLÍTICAS}

A ACONERUQ teve sua criação no ano de 1997, sendo organizada enquanto um "fórum de representação das comunidades quilombolas do Maranhão" (ESTATUTO, 2007, 01). Esta associação, pelo próprio período histórico e vínculos estabelecidos, foi assessorada diretamente por setores do Movimento Negro, como o CCN (Centro de Cultura Negra), seja em sua constituição, seja nos primeiros trabalhos desenvolvidos pela entidade. Nesse sentido, o debruçar do Movimento Negro sobre a realidade das comunidades quilombolas do Maranhão remete diretamente a figura de Mundinha Araújo, historiadora e militante do Movimento Negro, que a partir de sua curiosidade e empenho começa a tentar compreender a situação dessas comunidades ainda na década de 1970, como situa a autora ao historiador Adelmir Fabiani por meio de carta: 
Ouvira falar que no interior, isto é, nos centros de alguns municípios existiam lugares onde 'só morava pretos' e que esses pretos não se misturavam com ninguém, ou seja, não havia qualquer vestígio de miscigenação entre eles. Naquele tempo a minha curiosidade como negra em saber mais sobre esses negros da zona rural levou-me a contatar aqui mesmo em São Luís com pessoas dos municípios, viabilizado a possibilidade de servirem de intermediárias quando chegasse até lá e tivesse que deslocar-me para os povoados (FABIANI apud ARAÚJO, 2007).

O trabalho de Mundinha Araújo ocorreu de forma voluntária, realizando visitas a comunidades rurais, a partir de contatos com representantes e lideranças locais, se debruçando sobre os modos de viver e fazer existentes nessas comunidades, em seus calendários de festas, práticas socioculturais e memórias do pós-escravidão, entre os anos de 1976 e 1978. Nas primeiras comunidades visitadas, não ocorre a identificação de conflitos fundiários, todavia, como situa a própria Mundinha Araújo, isso não significa que não existissem, pois "dezenas de comunidades já vinham lutando desde os anos 40, 50 e 60 contra as invasões de pessoas de fora que resultavam na expulsão dos antigos moradores nas terras conhecida como "dos pretos"' (FABIANI apud ARAÚJO, 2007). Antes mesmo do Movimento Negro assumir a causa das comunidades quilombolas no Maranhão entre meados dos anos de 1970 e 1980 com a fundação do CCN, estas comunidades já vinham se organizando e tentando resistir contra a invasão de suas terras por parte de grileiros e fazendeiros, como situa Mundinha Araújo ao historiador Adelmir Fabiani:

As comunidades negras rurais Santo Antônio dos Pretos, Bom Jesus dos Pretos, Santa Rosa dos Pretos, Jacareí dos Pretos e outras, vinham se organizando contra a grilagem, antes mesmo de o movimento negro assumir a causa, inclusive "arrecadando recursos entre eles mesmos para pagar honorários de advogados, despesas cartoriais, viagens para a capital e outras" FABIANI apud ARAÚJO, 2007).

Nesse sentido, é com a criação do CCN em 1979 que ocorre a centralização das demandas das comunidades quilombolas em uma entidade sediada em São Luís, dando destaque as situações de privação, conflitos agrários e as necessidades específicas destas comunidades. A partir do conhecimento de Mundinha Araújo, somadas às articulações da recém-criada entidade surge um projeto, tendo em vista cobrir a realidade agrária e as demandas das comunidades quilombolas, intitulado PVN (Projeto Vida de Negro) que vigorou entre 1988 e 2005 em parceria com a SMDH (Sociedade Maranhense de Direitos Humanos).

Tal projeto considerava significativamente dados e a produção pioneira de Mundinha Araújo e outros intelectuais negros, como João Francisco dos Santos ${ }^{2}$ e Luiz Alves Ferreira ${ }^{3}$, enquanto fundadores do CCN, agregando a possibilidade de financiamento e a disponibilidade de pesquisadores e militantes do Movimento Negro em seus trabalhos de campo, pesquisa cartorial e outras tarefas. O projeto visava colocar em prática o artigo 68 da Constituição Federal, bem como registrar modos organizativos e práticas socioculturais existentes nas comunidades quilombolas,

\footnotetext{
2 Um dos integrantes da equipe fundadora do Centro de Cultura Negra do Maranhão (CCN/MA) e foi o primeiro presidente do Diretório Municipal do Partido Democrático Trabalhista (PDT) em São Luís. Foi também o secretário de Estado da Igualdade Racial na gestão do governador Jackson Lago (2007-2009).

${ }^{3}$ Médico, professor aposentado da Universidade Federal do Maranhão (UFMA), um dos integrantes da equipe fundadora do Centro de Cultura Negra do Maranhão (CCN/MA).
} 
buscando o intermédio junto ao poder público tanto em esfera estadual quanto federal nos processos de efetivação de garantias legais, tendo "sido um lugar de reflexão sistemática sobre as mobilizações quilombolas, acoplando o conhecimento militante às memórias locais de resistência" (ALMEIDA, 2002, p. 15).

Tal projeto, contou com o apoio significativo de entidades externas, bem como com recursos oriundos do governo Federal em que "as atividades desenvolvidas junto às comunidades negras pelo PVN tiveram apoio da Fundação Ford (EUA), a Oxfam (Inglaterra), a EZE atual EED, Alemanha), a Cese (Bahia) e a Fundação Cultural Palmares/Ministério da Cultura" (FABIANI, 2009, p. 11).

Entre pequenos encontros municipais, somados ao empenho das comunidades quilombolas e a assessoria do CCN, surge em 1997 a ACONERUQ. Tal entidade vinha a substituir a Coordenação Estadual Provisória dos Quilombos Maranhenses (CEPQM), criada em 1995 e com o intuito de nuclear as demandas das comunidades quilombolas em processo de organização graças aos trabalhos do PVN. Nesse sentido, a criação da ACONERUQ está ligada diretamente as atividades do $\mathrm{CCN}$, nos processos de organização possíveis através do PVN, como pontua Ivo Fonseca, primeiro coordenador da ACONERUQ, na sede do CCN, em 2013:

A montagem da ACONERUQ vai surgindo naturalmente e a gente tinha o Centro de Cultura Negra que dava o foco nos encontros regionais e estaduais. Só para você ver, nós fomos oficializar a entidade no quinto encontro estadual. Teve várias reuniões nos municípios para explicar como era as coisas e aí eles já diziam por que a gente não faz uma organização estadual?!

Dessa forma, somando a vontade de criação de uma entidade específica de lideranças quilombolas, um cenário com uma presença significativa de comunidades quilombolas em processo de organização e conhecimento de realidades de dificuldades partilhadas, somados as limitações institucionais da Coordenação Provisória e a necessidade de abranger as demandas em nível estadual, fizeram surgir a ACONERUQ, após seminários ocorridos nos municípios de Cururupu, Mirinzal, Alcântara e Turiaçu ao longo do ano de 1996 e da realização do V Encontro das Comunidades Negras Rurais no Maranhão. Nesse sentido, as bases estruturais de criação da entidade se encontravam nos municípios de Itapecuru-Mirim, Penalva, Caxias e Codó (PVN, 2005, p. 50). Dessa forma, a entidade foi pensada como um fórum de representação das comunidades quilombolas que garantisse a interface junto ao Estado, o acesso a políticas públicas e certas garantias formais. Conforme situa Ivo Fonseca em entrevista, ocorrida em 2013, na sede do CCN:

O foco principal era trabalhar para que as comunidades conquistem seus territórios e no período que eu fui coordenador eu encaminhei muitos processos para o INCRA e de outro lado que nós trabalhava era a questão da formação política nas comunidades, era a base entender o processo na ACONERUQ, entender a formação. Entender o processo vindo de baixo para cima e não de cima para baixo, então nós tinha essa capilaridade. Outro ponto que nós trabalhava era a questão das normas constitucional. Quando a ACONERUQ começa nós também passamos por isso em nível nacional, porque não adiantava nós estarmos aqui e as portas estarem fechadas quanto a esses ordenamentos. Nós também trabalhamos políticas básicas como educação, saúde, estradas. 
Em seu trabalho de representação, a ACONERUQ lida com um enumerado de situações e demandas oriundas das comunidades quilombolas, que envolvem desde políticas de titulação e regularização fundiária, que são realizadas por órgãos federais e estaduais, como o INCRA (Instituto Nacional de Colonização e Reforma Agrária) e ITERMA (Instituto de Colonização e Terras do Maranhão), até o acesso a políticas públicas de educação, moradia, infraestrutura, água potável, insumos agrícolas, etc.

Outro aspecto importante, se refere a necessidade de uma entidade desse tipo, que funcione como um ente formal perante o Estado, capaz de representação, firmamento de contratos, arrecadação de valores e que ao mesmo tempo, mantenha as comunidades organizadas, nucleadas e mobilizadas partir desse modelo institucional. Nesse sentido, tem-se uma interessante fala de Maria Eunice Machado (2015), a dona Nice, militante da ACONERUQ e uma das fundadoras da entidade:

\begin{abstract}
A ACONERUQ é a associação quilombola do estado do Maranhão, então essa associação foi criada para representar uma entidade jurídica porque o nosso movimento negro já tem mais de 300 anos, tá. Nós que 'vem' do Maranhão, nós 'precisava' de uma entidade jurídica que apresentasse 'nós', né. Porque quando você vai para uma luta, vai para qualquer trabalho, eles precisam que a gente apresente um documento lá pela entidade e 'nós' era só movimento, hoje nós somos entidade porque tem um documento que apresenta 'nós' juridicamente como entidade. Então, ela foi criada através disso aí, para representar 'nós' em todo lugar do estado do Maranhão, os quilombolas.
\end{abstract}

Um dado interessante a partir da fala de dona Nice, refere-se a importância dada as formalidades por parte dos quilombolas que fundam a ACONERUQ, na capacidade de representação jurídica perante o Estado e frente a outros segmentos sociais. Para ela, já não se trataria apenas de um movimento social justamente por essa capacidade, pela possibilidade de "representação" e apresentação de "documentos". Assim, a ACONERUQ funciona como uma entidade formal, capaz de assegurar certa visibilidade e institucionalidade frente a antagonistas ou para com possíveis parceiros. A possibilidade de representação das comunidades pela ACONERUQ se dá graças a filiação das associações de moradores dessas comunidades quilombolas à entidade, o pagamento de taxas de anuidade e a possibilidade de formação de chapas que concorrem eleitoralmente a gestão por determinado período de tempo (ESTATUTO, 2007, p.02; p.08).

Já o MOQUIBOM ganha destaque a partir de ocupações a órgãos públicos e passeatas no ano de 2011 e com denúncias públicas sobre assassinatos de lideranças quilombolas e morosidade estatal nos processos de titulação de territórios. Nesse sentido, o surgimento do movimento está relacionado aos trabalhos da CPT (Comissão Pastoral da Terra) junto a comunidades quilombolas no interior do Maranhão, mais especificamente na região da Baixada maranhense, região em que o movimento surgiu. Esses trabalhos se deram, sobretudo, ao dar visibilidade às garantias Constitucionais existentes desde 1988, bem como auxiliando as comunidades nos processos de auto identificação e elaboração de relatos sintéticos a serem enviados a FCP (Fundação Cultural Palmares), como forma de assegurar a obtenção do certificado emitido pela Fundação, um dos passos no processo de titulação territorial das comunidades quilombolas. Nesse sentido, as ações do MOQUIBOM giram em torno de pequenos encontros que ocorrem nas comunidades quilombolas, pequenas ações em nível local na organização dessas comunidades, 
bem como encontros maiores, em que ocorriam com a troca de experiências e vivências, a partir da construção de laços e da demonstração de pertenças étnicas em comum e situações de opressão compartilhadas por esses sujeitos. Como situa Marivânia Furtado (2012):

Reunidos a partir da mística da terra como dom de Deus e direito de todos que dela precisam, o primeiro encontro da articulação MOQUIBOM aconteceu no sítio dos "padres" em Mangabeira, povoado de Santa Helena. Embalados e motivados por cânticos que denunciam o descaso do poder público e a necessidade de luta dos despossuídos, essa articulação marcou o primeiro semestre de 2011 com mobilizações jamais vistas, sobretudo por se tratar de um movimento quilombola (FURTADO, 2012, p. 260-261).

Parte desses encontros ocorriam também em instalações ligadas a Igreja Católica, como o mencionado "sítio dos padres" no município de Mangabeiras, reunindo comunidades quilombolas, padres, estudantes universitários e setores próximos a CPT e alguns sindicatos. Nesse sentido, as ações da CPT se davam principalmente pela interlocução que a entidade confessional tem para com as comunidades rurais, pelo prestígio gozado pelos padres e pela atuação destes na mediação de conflitos e na resolução de questões pontuais. Nesse sentido, a CPT também funciona como um foco de mediação entre as comunidades quilombolas e o Estado, na medida em que ocorrem conflitos fundiários. Parte dessa mediação também ocorre por outras entidades, como o Conselho Indigenista Missionário (CIMI), Comissão Pastoral da Pescadores (CPP), Pastoral da Juventude (PJ), e outras entidades confessionais ligadas a Igreja Católica, situando esta instituição e as entidades a ela vinculadas como importantes atores sociais no campo. Como situa Alfredo Wagner Berno de Almeida (2014):

Ao se disporem como exercendo uma mediação dos antagonismos na área rural e, em decorrência, funcionando como interlocutores obrigatórios frente ao Estado, as instituições religiosas pressionam a estrutura agrária como forças sociais organizadas, deslocando politicamente outros mediadores externos porventura existentes. Ao eclodirem quaisquer conflitos de terra, que envolvam camponeses, grupos indígenas e latifundiários, eles passariam a ser tratados necessariamente pela intermediação desses dois centros de poder: Estado e Igreja (ALMEIDA, 2014, p. 70).

Essas ações de mediação de conflitos no campo, de lado dão lugar de destaque para a Igreja, seja frente o Estado, seja para com as comunidades rurais que passam a procurar suas entidades para a resolução de questões. Nesse sentido, é a partir desse lugar de mediação privilegiado que ocorre o incentivo para a criação de um movimento social próprio de comunidades quilombolas, como é o caso do movimento supracitado. Dessa forma, O MOQUIBOM reivindica a rubrica de movimento social por conta de sua não institucionalidade, ou seja, ausência de sede fixa, CNPJ (Cadastro Nacional de Pessoa Jurídica), ou qualquer formalidade além de seus membros agremiados e seu poder de mobilização junto às comunidades, realizando ocupações a órgãos públicos, passeatas e greves de fome, como forma de visibilizar a luta de comunidades quilombolas por direitos territoriais assegurados Constitucionalmente. 
Como dado interessante tem-se a relação entre a CPT e o MOQUIBOM. Para vários integrantes do MOQUIBOM a entidade seria uma mãe, responsável por ter gerado um "filho" a partir de si, de quem é responsável, tendo zelo e cuidado pelo mesmo. Dessa forma, mais do que um auxiliar, uma parceira esporádica, a CPT se apresenta como principal entidade de apoio às ações do MOQUIBOM e com ele tendo uma relação estreita, que por vezes se confunde, na medida em que cede parte de suas instalações, orçamento e quadros no auxílio deste movimento. Como situa Catarino Borges, o Santinho, em entrevista ocorrida na sede da CPT em São Luís, em 2015:

A relação da CPT e do movimento é uma relação $100 \%$ mesmo, é $100 \%$ porque na verdade a gente considera nós que somos da coordenação da frente do movimento, nós consideramos a CPT como mãe do MOQUIBOM, porque na verdade ele teve no ventre, botou para fora, é igual menino na barriga de uma mãe, botou para fora, sentou, engatinhou e tá começando a andar, mas sempre ao lado da CPT. A CPT foi nossa mãe e a mãe nunca abandona o filho, até hoje, espero que de amanhã em diante não abandone também, que é um parceiro, uma mãe que criou.

Nesse sentido, a relação entre delegação e mediação parece caminhar numa linha tênue, em que "membros das instituições confessionais empreenderam o risco calculado de agir ou de falar em nome de camponeses ou de grupos indígenas, como se a delegação consistisse numa etapa necessária para alcançarem uma existência coletiva e, portanto, de direitos políticos que configuram a plenitude da cidadania (ALMEIDA apud BOURDIEU, 1990, p. 192). Portanto, a relação entre os quilombolas organizados no MOQUIBOM e a CPT, parece ter tons de dependência e não estar livre de certa dose contradição, na medida em que os quilombolas parecem estar estreitamente vinculados a formalidade assegurada por esta entidade, seus contatos e apoio de profissionais liberais a ela ligados, as possibilidades ofertadas em termos de divulgação e exposição de situações limite em meios eletrônicos ou impressos, assessoria e mobilização, através da transferência de prestígio, auxílio de advogados e outros profissionais, bem como a notoriedade e carisma que a entidade tem entre alguns setores sociais.

Por outro lado, pelo próprio prestígio gozado, as entidades confessionais têm a possibilidade de mobilizar e politizar a partir de novas matrizes discursivas os setores a ela vinculados. É assim que a partir de um "trabalho de repensar" de suas ações que a CPT passa a dar destaque à categoria quilombo em contraposição a categoria de posseiro nas atividades da entidade. Esse repensar reflete tanto o reconhecimento por parte da entidade das categorias e legislação específicas para o trato com a questão quilombola de maneira mais abrangente, como o entendimento da generalidade desta questão ao falar do Maranhão, isto a partir de sua própria inserção e atividades no meio rural. Como situa Fábio Silva, ex-agente pastoral da CPT, em entrevista ocorrida na cidade de Pinheiro em 2015:

A CPT Pinheiro, da qual eu faço parte, sempre teve um trabalho ligado as comunidades tradicionais, ribeirinhos, quebradeiras de coco, posseiros e até que a gente foi conhecendo essa discussão das comunidades quilombolas, a questão da legislação e tudo e muitas das comunidades que a gente trabalhava com a categoria de posseiros, né, de posseiras, de posseiros, de comunidades quebradeiras de coco, são também comunidades quilombolas. Começamos o trabalho, eu sempre 
coloco a parte com mais força a partir de 2010, um trabalho mais forte no município de Serrano e essas comunidades que a gente já conhecia na baixada, com esse trabalho, foi despertando o conhecimento de outras, também a gente foi levando essa informação sobre as comunidades quilombolas, os direitos que elas tinham, os direitos que elas tem e a gente sentiu que essas comunidades tavam, elas não tinham visibilidade nas suas lutas. Elas tavam lutando de forma isolada, cada comunidade lutando, resistindo, para manter os seus territórios, umas perderam, outras conseguiram manter em parte, outras conseguiram seu território, mas cada comunidade vinha lutando de forma muito separada, sem unir. Não existia aquele sentimento de um povo, de um povo quilombola. Existiam as lutas que vem desde a década de 1960, 1970, então essas lutas inclusive já existiam, então onde elas aparecem no caderno de conflitos da CPT de 2010 e 2011, aonde o caderno de conflitos da CPT dá um salto, dá um salto e o Maranhão desponta como o estado com maior número de conflitos. Mas não era que não existia os conflitos, os conflitos já existiam, estavam lá, não era publicizado, não tinha visibilidade de luta. Então, eu acredito que a grande sacada aí do trabalho da CPT foi juntar essas comunidades, né; colocá-las num encontro e começar a deixar eles se encontrarem e ver que os problemas eram comuns, né, o foro, a questão do impedimento de fazer uma casa, impedimento de buscar seus extrativismos do qual eles utilizavam, então esse, eu acho essa grande sacada de juntá-los e eles verem que o problema era comum e os unia pelas mesmas razões, então eu acho que isso foi um passo importante, a partir daí, das comunidades se encontrarem e começar a pensar que era necessário pensar uma lutar que desse direito aos territórios.

Nesse sentido, a partir da fala de Fábio Silva se tem a importância das ações da CPT no surgimento do MOQUIBOM. Como primeiro ponto, temos um repensar categorial a luz da própria realidade maranhense, que coloca sob suspeição o conceito de posseiro, historicamente utilizado pela CPT e Igreja Católica no trato de conflitos fundiários, e traz à tona formas de uso e pertenças étnicas que remetem a especificidade de parte significativa da população das comunidades rurais maranhenses, dando vazão ao conceito de comunidades quilombolas para o trato desta realidade e dos conflitos fundiários nela existentes.

Como segundo ponto, temos que a partir dos trabalhos da CPT passa a ter maior organização das lutas que já existiam por parte das comunidades quilombolas, agora munidas de certo referencial, apoiadas pela entidade confessional e conhecendo sua realidade, era também compartilhada por outras comunidades em situação semelhante.

Situações de pagamento de foro, típica forma de arrendamento da terra, pago através de produtos em espécie, como farinha ou arroz; situações de impedimento de construção de casas por parte de supostos proprietários para com as comunidades e outras situações de privação que passam a ser utilizadas pela CPT como formas de opressão vivenciadas pelas comunidades quilombolas que seriam recorrentes na realidade destas.

Outro dado refere-se à visibilidade dada as lutas dessas comunidades, bem como a situações de conflitos fundiários que a CPT passa a dar a partir de suas publicações anuais, como os Cadernos de Conflitos no Campo, especialmente nos anos de 2011, 2012 e 2013; entrevistas, através de publicações na internet e outros meios. Dessa forma, tem-se um processo de organização das comunidades 
ocorrendo a partir das ações da CPT, criando um sentimento de "povo quilombola", como comentado anteriormente por Fábio Silva.

Como uma questão interessante, se tem as possíveis motivações que podem ter gerado a criação de um novo polo de organização das comunidades quilombolas, para além da ACONERUQ. Como um primeiro entendimento, tem-se que o surgimento deste movimento social se deu pela ausência de atividades da ACONERUQ em certas regiões e municípios do Maranhão, como pontua Maria José Palhano, antiga coordenadora da ACONERUQ em entrevista em 2015:

\begin{abstract}
Eu vejo a criação do MOQUIBOM como uma forma dos quilombolas que não estavam sendo assistidos e que a ACONERUQ tava deixando uma lacuna grande, se organizarem, se reorganizarem. E o que eu acredito, eu creio de verdade, que é bom. Não é ruim. Eu só acho que a gente não pode e nem deve se separar, acho que a gente deve andar juntos, juntar as forças porque quando a gente se junta a gente é forte. Quando a gente se separa a gente enfraquece. Quando uma toca para um lado, não dá pra fazer um amontoado, porque se dividiu, eu comparo isso com dois elos da corrente, um elo sozinho ele não faz nada, ele é muito frágil, mas quando você junta dezenas, centenas de elo, você tem uma corrente. Aí ela é forte.
\end{abstract}

Essa lacuna na representação das comunidades quilombolas do Maranhão é explicada em parte pela situação precária em que a entidade se encontrava. Porém, esse assunto mostrou-se de difícil trato, uma vez que exigia a exposição de questões internas da ACONERUQ, que giram em torno das prestações de contas, processos judiciais, uso dos recursos obtidos através de convênios com o governo federal e estadual e eleições de chapas para coordenação da entidade, o que fugia aos limites de confiança e a possibilidade de exposição dos sujeitos pesquisados. Nesse sentido, parte da discussão sobre ética nas pesquisas antropológicas tem girado em torno do:

...consentimento (formal ou informal) do grupo investigado, o tipo de informação que o pesquisado deve obter da pesquisa de que participa, a capacidade legal e intelectual dos entrevistados de entender a pesquisa proposta e as formas de coerção que podem estar envolvidas nessa relação (DEBERT,2004, p.45).

O intuito da pesquisa não era expor a uma situação vexatória antigas lideranças e membros da ACONERUQ ou mesmo trazer à tona dificuldades na gestão dos recursos gerenciados pela entidade. Portanto, houve um cuidado calculado com "os riscos envolvidos na publicação dos resultados, porque nossas conclusões não podem constranger, humilhar ou trazer prejuízos para as populações estudadas" (DEBERT, 2004).

Por outro lado, como forma de diferenciar sua gestão das anteriores, responsáveis por genericamente, colocar a ACONERUQ em situação de "abandono" e "descrédito", Maria José Palhano (2015), mesmo com certas ressalvas e limites, expunha sua opinião quanto a situação da ACONERUQ, não se privando de sempre que se sentindo invadida, solicitar que o gravador fosse desligado, pois "isso não pode ficar gravado":

Eu acredito que com relação a ACONERUQ tava uma coisa muito debilitada porque apesar de dizermos que a ACONERUQ tava aqui, em defesa dos territórios quilombolas, em defesa da 
comunidade quilombola, naquele momento ela não tava em defesa nem dela mesmo.

E continuava a comentar sobre o início de suas atividades, quando passou a compor a gestão da entidade como parte de uma "junta governativa" dada a situação de débitos para com funcionários e o imóvel que servia de sede para a entidade, este tendo inclusive sido alvo de ordem judicial de despejo, como comenta Maria José Palhano (2015):

\begin{abstract}
Quando eu cheguei na ACONERUQ, eu costumo dizer que a ACONERUQ estava num estado bem precário, ela não tava nem mesmo mais sendo convidada para nada porque a forma como deixaram ela, deixaram ela de uma forma muito decadente, eu posso dizer assim, porque quando eu cheguei na ACONERUQ era um estado total de abandono, não tinha acontecido eleição, e eu vim para uma junta governativa enquanto já como presidente da junta, e para organizar a eleição porque não tinha acontecido a eleição segundo os antigos por falta de recursos, e ao chegar eu realmente constatei que era isso que tinha acontecido, porque uma semana depois que eu cheguei, chegou uma ordem de despejo, eram muitos débitos, aluguéis atrasados, funcionários atrasados, era muita coisa que tava pendente. Mas aí, depois de organizar o processo eu soube que eu também poderia me candidatar, aí eu me candidatei e ganhamos a eleição, uma eleição muito cheia de conflitos, porque tinha interesses particulares por trás das pessoas que não queriam que acontecesse eleição, mas aconteceu, né. $E$ a gente ficou como coordenadora geral, então eu fui aí para frente de julho de 2010 lutar para ver se tirava, se resgatava pelo menos a credibilidade política da instituição.
\end{abstract}

Por outro lado, no entendimento de quilombolas pertencentes ao MOQUIBOM, o seu surgimento não está ligado propriamente a ausência de atuação da ACONERUQ em certas regiões do Maranhão, a sua inexistência em certos municípios ou comunidades, mas pelo tipo de ações realizadas pela entidade. Nesse sentido, O MOQUIBOM traria a tona formas de luta, instrumentos de mobilização e exposição das situações vivenciadas pelas comunidades quilombolas que estariam além dos limites da institucionalidade proposta ACONERUQ, como pontua em entrevista Catarino dos Santos Borges, o Santinho, membro do MOQUIBOM (2015):

A gente não atua naquele local que a ACONERUQ atua menos, mas sim em todas as regiões que a ACONERUQ atuava e tá atuando, nós também 'tamo' atuando. Até mesmo porque o movimento surgiu pela necessidade, da ausência da ACONERUQ não só em dois, três pontos, mas sim nos quatro pontos do Maranhão, porque é uma entidade que é pra representar as comunidades tradicionais, principalmente as quilombolas. É para fazer a representatividade dessa questão. Então, O MOQUIBOM atua em todos os motes que a ACONERUQ atuava e tá atuando. Eu não tenho a ACONERUQ e o MOQUIBOM como uma divergência, entre aspas também, né, na verdade hoje a ACONERUQ era para tá com a gente, porque quando nós entramos, no início, chamamos eles para vir com nós. Então, eles achava que, não sei se é verdade ou não, mas eles conversam que nós éramos uns doidos, com a questão do INCRA, para fazer as mobilizações, sem ter decisões nenhum 
e sem ter capacidade de fazer o que nós fizemos. Pois nós mostramos para eles que nós éramos pequenininhos, hoje 'tamo' grande, 'tamo'com articulações maiores, né, éramos pequenininhos, mas fazemos a linha de grande. Então, essa linha de grande hoje surgiu em nível nacional. Então, o medo deles hoje é porque eles tiveram conhecimento que nós não éramos na verdade o que eles pensavam. Eles pensavam que na verdade, com certeza a CPT só ia botar nós na frente e deixar nós ir embora, caminhar, mas do início até hoje a CPT é nossa mãe e jamais vai abandonar nós.

Aqui, Catarino Borges, comenta uma das primeiras ocupações públicas realizadas pelo MOQUIBOM no ano de 2011, esta ocupação, situada na superintendência do INCRA/MA gerou certa situação de animosidade e farpas públicas trocadas entre os dois polos de organização quilombola. De um lado, o MOQUIBOM se apresentava com um setor radical, realizando uma das primeiras greves de fome em ocupações quilombolas, junto a protestos públicos e caminhadas, denunciado assassinatos no campo e a impunidade no caso da morte da liderança Flaviano Pinto, liderança da comunidade quilombola de Charco, alvejado por tiros.

Por outro lado, a ACONERUQ aparecia como a entidade que gozava de credibilidade frente o Estado e instituições públicas, mas sem qualquer controle ou possibilidade de intervenção na ocupação realizada, sem autoridade sobre os quilombolas acampados.

Outro aspecto pontuado em entrevista por Naildo Braga (2015), liderança do MOQUIBOM, seria o destaque dado para os processos de titulação dos territórios quilombolas por parte do movimento. Esse seria a principal pauta do movimento em suas ocupações e demais ações. Nesse sentido, para os quilombolas situados no MOQUIBOM esse seria um diferencial do quanto a ACONERUQ:

\begin{abstract}
MOQUIBOM surgiu e atua principalmente em defesa da titulação dos territórios para as comunidades quilombolas. Porque foi uma necessidade que se alastra aí por muito tempo a questão da titulação das terras das comunidades quilombolas e que até então as instituições que existiam, os movimentos que existiam, nesse sentido, não tavam correspondendo à altura das demandas e também das necessidades que essas comunidades enfrentam. Então foi daí que surgiu o MOQUIBOM e daí que ele atua principalmente nessa linha aí, de titulação das áreas das comunidades quilombolas.
\end{abstract}

Nesse sentido, há aqui o apontamento quanto a existência de rivalidade entre os segmentos que organizam as comunidades quilombolas no Maranhão, havendo certa disputa, ou mesmo, desconforto generalizado entre estes quanto divisão de espaços públicos e desentendimentos na leitura das ações empreendidas e formas de compreensão do cenário político por ambos os polos organizativos.

Esse fator se mostrou como um adicional nas pesquisas realizadas, na medida em que o caminhar em campo, a tentativa de estabelecimento de laços que vislumbrassem 0 acesso simultâneo a informações e projetos relativos ao MOQUIBOM e a ACONERUQ era um "pisar em ovos", que em vários momentos, o campo mais parceria um "campo minado", dadas desconfianças e cobranças por parte dos sujeitos pesquisados. Porém, o mesmo campo cheio de minas, se mostrou um espaço de reflexão sobre o métier antropológico, na medida em que mais do que produzir literalizações, ou mesmo esquemas de tipificação social, em nosso ofício tem sido considerado desafiador uma produção antropológica que busque devolver o que 
estudamos a sua cotidianidade, ao seu lugar comum e simples, devemos perceber que

\begin{abstract}
...parte de nossa tarefa consiste em descobrir por que aquilo que as pessoas que estudamos fazem e dizem parecem-Ihes, eu não diria evidente, mas coerente, conveniente, razoável. Mas a outra parte consiste em estar sempre se interrogando sobre até que ponto somos capazes de seguir o que elas dizem e fazem, até que ponto somos capazes de suportar a palavra nativa (GOLDMAN, 2006, p. 167).
\end{abstract}

Assim, o campo aparece menos um laboratório frio e asséptico e mais como um espaço carregado de contradições, esquemas de poder e disputas, em que de um lado os sujeitos são carregados de intencionalidades e desejos, por outro, constantemente nossas capacidades são colocadas à prova e dribladas pelas experiências ali vivenciadas e partilhadas com esses sujeitos.

Por fim, comento uma interessante estratégia adotada pelo MOQUIBOM, a aproximação de outros povos e comunidades tradicionais, tendo em vista não apenas realizar grandes atos e protestos públicos relacionados a processos de demarcação e titulação de territórios, situações de violência contra lideranças ou grandes empreendimentos públicos ou privados em rota de colisão com as vidas destas comunidades, mas a possibilidade de viver "vidas em aliança", vidas partilhadas em meio às diferenças e similitudes.

\title{
3. "VIDAS EM ALIANÇA": MOQUIBOM, TEIA DE POVOS E COMUNIDADES TRADICIONAIS E DISPUTAS TERRITORIAIS NO MARANHÃO
}

Em meio ao meu trabalho de campo, acompanhando protestos e ações do MOQUIBOM não era atípico, entre as mobilizações de comunidades quilombolas, ter a presença de outros segmentos sociais, como quebradeiras de coco babaçu, indígenas, pescadores artesanais e camponeses, por exemplo. Esses sujeitos estavam também expressando suas demandas, dividindo situações de privação e ecoando pautas em conjunto com comunidades quilombolas. Nesse sentido, o MOQUIBOM tem investido no trabalho com diferentes segmentos sociais, "com todos os povos", dando ênfase a possíveis alianças a serem firmadas com esses segmentos sociais, conforme falas de suas lideranças. Ao ser perguntado como se dá esse trabalho, Borges (2015) pontua que:

A partir do momento que é uma comunidade tradicional, indígena, quilombola, ribeirinho, então, abraçamos a causa deles. Nós não podemos dividir nosso povo. Nós dependemos do nosso território livre. É o objetivo do MOQUIBOM ter uma bandeira levantada, ter território livre. E o território livre onde tenha saúde, educação, o lazer também, o respeito, porque o racismo hoje é muito grande, é muito grande nas comunidades tradicionais, principalmente com nós quilombolas, principalmente o pessoal que tá na coordenação do MOQUIBOM, até hoje tem discriminação e racismo contra nós. "Tamo" fazendo a nossa parte, defender os territórios em prol da liberdade dos negros.

Nesse sentido, o MOQUIBOM tem investido em ações que comunguem com outros segmentos, sobretudo com indígenas, pescadores artesanais comunidades extrativistas e camponesas; o que extrapola as pautas das 
comunidades quilombolas em si, dando dimensão do que significa a demanda territorial para estes sujeitos. Essa estratégia já havia sido registrada em ocupações ao INCRA em 2011, quando indígenas estiveram presentes nas primeiras ocupações deflagradas pelo movimento (SOUSA, 2013). As tentativas de estreitamento de laços e criação de formas de alianças com segmentos indígenas e outros têm girado, sobretudo, na defesa de direitos territoriais, com a tentativa de se criar um polo expandido de protestos, em tom organizado e ações afinadas, criando alianças entre as comunidades tradicionais na defesa de direitos e garantias a partir de marcos constitucionais.

Assim, vemos a produção de uma comunidade extensa, sendo esta, sobretudo, uma comunidade política, em que o movimento de comunidades quilombolas estabelece pertencimentos e laços, estes sendo moldados no sentido de possibilitar afinidades, tendo em vista a defesa de certas conquistas, bem como buscando estreitar as lutas territoriais com segmentos sociais considerados semelhantes. É dessa forma, que se cultivam vínculos relacionados à crença de uma situação análoga entre indígenas e quilombolas, ou mesmo na seleção de semelhanças a partir de entendimentos que percebem similaridades entre as vivências, a valorização de estilos de vida vistos como diferentes e particulares (ARRUTI, 2014).

A partir de pistas dadas por M. Banton (1979), um grupo étnico se constituiria na reversão e positivação das marcas impressas pelo racismo a determinados agrupamentos sociais, na positivação dos estigmas, ocorrendo a valorização dos indivíduos entre si e dos pertencimentos que os ligam através das marcas da estigmatização. Seguindo essa linha de raciocínio, é possível perceber a criação de uma comunidade extensa por parte do MOQUIBOM, ao tentar canalizar de forma impulsionadora os estigmas considerados análogos a indígenas e quilombolas, ou seja, a etnicidade também deve ser vista como o constructo que almeja a criação de laços e pertencimentos baseados em uma comunidade política extensa que percebe como se impõem cicatrizes e lugares sociais que podem ser vistos como semelhantes entre si. Assim, em meio a um movimento que se esforça para agregar comunidades quilombolas dentro de si, há constantemente também o esforço para a criação de redes de solidariedade próximas de outros segmentos sociais.

Com a expectativa de troca de vivências e conhecimentos, foi realizado o II encontro dos povos e comunidades tradicionais, o II Encontrão, como é conhecido entre os quilombolas, na comunidade de Taquaritiua, comunidade indígena da etnia Gamella que reside no interior do município de Viana, Maranhão. Neste encontro, ocorrido entre os dias 27 de fevereiro e $1^{\circ}$. de março de 2015 , houve a participação do MOQUIBOM, bem como de quebradeiras de coco ligadas ao Movimento Interestadual de Quebradeiras de Coco Babaçu (MIQCB), indígenas de diferentes etnias (Krikatí, Krenyê, Guajajara, Gavião, Ka'apor e Kayapó), posseiros, padres e freiras católicas e entidades confessionais, como CIMI e CPT.

Durante três dias em um barracão de palha decorado com bandeiras, adornos coloridos, cofos de palha, faixas, tambores, potes de barro e símbolos que remetiam aos segmentos presentes, cerca de 200 pessoas debatiam sobre formas de organização e vivências em comum entre as comunidades presentes, sob o lema "territórios livres - tecendo o bem viver". Um dado interessante refere-se aos agentes confessionais ligados ao MOQUIBOM: são os mesmos que passam a desenvolver trabalhos com a comunidade indígena Gamella, com pautas junto a Fundação Nacional do Índio (FUNAI), o que reforça laços entre quilombolas membros do MOQUIBOM e os Gamella, bem como cria a possibilidade de desenvolver estratégias em comum.

Em meio às falas de apresentação no II encontro, para Pe. Clemir Batista 
(2015) o que mais ligava e ao mesmo tempo sintetizava os diferentes segmentos ali presentes eram os seus modos de vida diferentes da lógica capitalista, suas práticas antagônicas a esse sistema socioeconômico:

A memória dos nossos pés, de onde passamos, de onde pisamos e o que temos vivido em nossos territórios não é passado. É preciso atualizar isso, lutar por isso. São os nossos rituais que lembram quem somos, que dizem sobre nós. É preciso valorizar isso. Nosso modo de vida é baseado na produção livre e sábia. Nosso modo de vida não nos escraviza, temos autonomia, tempo para nossa vida e uma relação com a natureza que não é para a produção.

A partir do exposto por Pe. Clemir Batista, os segmentos presentes estariam unidos pelos seus modos de vida diferentes das práticas mercantis, de uma relação respeitosa para com a natureza, o que os tornaria similares entre si, aliados frente a antagonistas, na luta pela efetivação de direitos e garantias territoriais e um possível projeto de futuro em comum. Assim, se iniciam relatos dos presentes sobre problemas e tentativas de respostas que ocorrem nas próprias comunidades.

Para Genival, quilombola de Santo Antônio dos Pretos, no município de Grajaú, "se nós não se une não existia mais nada em nosso território, é na forma de cuidar das matas e dos nossos animais que tá a resposta"; já para Antônio, da comunidade quilombola de São João dos Britos, em Turiaçu, "na nossa comunidade tudo é coletivo, tudo tá para ser dividido"; por sua vez, Zé Maria, da comunidade de Mamurana, relata que "em nossa comunidade tem companheiro que se danou para tirar tudo quanto é madeira, tem companheiro que alimenta história para o dito proprietário. Queimaram a minha casa e de outro membro da associação"; para Gil Quilombola, "o território é o nosso espaço para viver, é o lugar de nossas festas, que reúne gente que nem mora lá e vai, é o espaço que faz falta".

Assim, são ressaltadas relações históricas de descaso, racismo e exploração que colocariam indígenas, quilombolas, ribeirinhos e camponeses em posição semelhante, simétricas em termos de grupos marginais ao sistema capitalista, bem como possíveis respostas para os problemas vividos. É nesse contexto que conheço que está sendo montada uma rede que articula esses segmentos a partir do que denominaram como Teia de Povos e Comunidades Tradicionais, no intuito de incentivar práticas de organização coletiva, formas de autogestão e experiências emancipatórias. Dessa forma, entendo que o lema "territórios livres - tecer o bemviver" é a tentativa de vincular as ações de indígenas, quilombolas e demais segmentos presentes em um único eixo de estratégias, a partir de um conceito em que caibam todos os presentes e ajude a fornecer possíveis respostas e formas de leitura das realidades presentes.

Para Rosimeire Diniz (2015), coordenadora do CIMI no Maranhão, o que uniria os presentes ali sejam eles indígenas, quilombolas e quebradeiras de coco, era uma situação de semelhança, de terem sido colonizados por uma lógica predatória e mercantil, por terem suas práticas e valores constantemente desrespeitados, acentuando que a colonização imposta aos indígenas e negros significou perdas, nos termos de:

Estarmos dominados. As pessoas, seus territórios, trabalho, natureza, a espiritualidade, modos de vida e mentes foram submetidos a um senhor. Nós fomos inferiorizados, mas fomos porque há alguém que nos obrigou a acreditar que existe um superior, um correto e que 
nós fazemos errado, somos feios e ignorantes.

Nesse sentido, ganham relevo práticas e projetos assentados na valorização de outras formas de relação dos seres humanos entre si e para com a natureza, projetos com modelos que se propõem como alternativa ao conceito de desenvolvimento e bem-estar, com a valorização de práticas e saberes indígenas e de comunidades quilombolas. Esse tipo de discurso é incorporado às falas dos presentes no encontro, no sentido de que tecer o bem-viver é defender os territórios, estar ao lado dos marginalizados, no combate ao latifúndio e ao agronegócio.

Este conceito parece oferecer expectativas para a tentativa de articulação entre indígenas e quilombolas no Maranhão, no sentido de aproveitar as práticas organizativas e de autogestão, práticas de respeito mútuo entre seres humanos e não humanos, numa relação que harmonize produção e equilíbrio da vida entre segmentos marginalizados.

Como eixo diretamente relacionado ao tecer o bem viver aparecem os territórios livres como balizador do II encontro, como uma pauta que relaciona diretamente esses segmentos reunidos e sua ligação com seus "espaços ocupados por significados" (GODÓI, 2014), o desejo que estas pessoas têm de ver seus territórios respeitados, bem como a possibilidade de denúncia, havendo não apenas trocas de experiências, como também o firmamento de compromissos entre os segmentos presentes a partir da criação da Teia de Povos e Comunidades Tradicionais, conforme carta emitida pelo acampamento:

\begin{abstract}
Compartilhamos nossos saberes e fazeres, o trabalho em mutirão, o respeito pelo tempo da terra, o cuidado com nossas águas, nossas matas, com os animais. Compartilhamos também nossas preocupações, angústias, temores, diante das diferentes ameaças e violências que nos cerca. Denunciamos o avanço do latifúndio, a mineração, o genocídio da juventude negra, promovida, inclusive, por agentes do Estado. Denunciamos ainda os megaprojetos, promotores de um suposto desenvolvimento, apoiados pela retirada dos nossos direitos, via poderes Legislativo, Executivo e Judiciário. Diante desta realidade, estamos assumindo um compromisso de tecer uma rede de povos e comunidades tradicionais com o objetivo de articular nossas lutas e resistências em vista da garantia e preservação dos nossos modos de vida e territórios demarcados pelos nossos pés (II ENCONTRO, 2015, p. 1).
\end{abstract}

Ao atentar para as diferentes territorialidades expressas, percebem- se mecanismos de uso, apropriação, criação de vínculos e formas de pertencimento, bem como aos processos de significação conferidos pelos sujeitos. Mais do que falar em mera função material ou de recursos naturais, atenta-se para dimensão simbólica, a ocupação constante feita pelas pessoas. Assim, os territórios são ocupados pela vida desses sujeitos, atravessados por suas formas de trabalhar, viver, compartilhar, se identificar mutuamente, bem como por suas angústias e temores, chamando atenção a recorrência com a qual estas remetem aos seus territórios, somando diferenças e agregando demandas.

\title{
4. CONSIDERAÇÕES FINAIS
}

O trabalho em questão buscou analisar as diferentes facetas do Movimento 
Quilombola no Maranhão. Para isso, expôs de forma genérica o processo de formação de seus segmentos, seja a ACONERUQ, seja o MOQUIBOM e suas devidas relações com entidades de mediação, chamou atenção também para as diferentes estratégias e leituras políticas em termos de (im)possibilidades de ação. Nesse sentido, registrou certa crença em instâncias de participação e gestão de políticas públicas por parte do primeiro segmento, e por outro lado, um setor mais movimentalista e adepto de esquemas de ação direta no segundo caso.

Por fim, registrou a estratégia de se estabelecer unidade com diferentes povos e comunidades tradicionais, tendo em vista a defesa de seus modos de vida e territórios, criado a possibilidade de "vidas em aliança", somando diversidade e identidade no que se tem chamado de Teia de Povos e Comunidades Tradicionais.

\section{REFERÊNCIAS}

AGIER, M. Pensar el sujeto, descentrar la antropología. Cuadernos de Antropología Social, Buenos Aires, n. 35, p.9-27, jul./dez. 2012. Disponível em: http://revistascientificas.filo.uba.ar/index.php/CAS/article/view/1360/1306. Acesso em 11 out. 2018.

ALMEIDA, A. W. B. Agionarmento Agônico: a trajetória de instituições religiosas como mediadoras de conflitos agrários na Amazônia. In: LACERDA, P. M. (Org). Mobilização social na Amazônia: a luta por justiça e educação. Rio de Janeiro: Epapers, 2014.

ALMEIDA, A. W. B. Terras de preto no Maranhão: quebrando o mito do isolamento. São Luis: ECN / SMDH / PVN, v.1, 2002.

ARRUTI, J. M. A emergência dos "remanescentes": notas para o diálogo entre indígenas e quilombolas. Mana, Rio Janeiro, v.3, n.2, out. p. 7-38, 1997. Disponível em: http://www.scielo.br/pdf/mana/v3n2/2439.pdf. Acesso em: 12 out. 2018.

BANTON, M. A idéia de raça. Lisboa: Edições 70, 1979.

CLIFFORD, J. A experiência etnográfica: antropologia e literatura no século $\mathrm{XX}$. 3.ed. Rio de Janeiro: UFRJ, 2008.

Clifford, J. A experiência etnográfica: antropologia e literatura no século $X X$. GONÇALVES, J. R. S. (Org.), 2. ed. Rio de Janeiro: Editora UFRJ, 2002.

CARTA DO II ENCONTRO DE POVOS E COMUNIDADES TRADICIONAIS, São Luís: Jornal Vias de Fato, 2015.

DEBERT, G. G. Ética e as novas perspectivas da pesquisa antropológica. In: OLIVEN, R. G.; MACIEL, M. E; ORO, A. P. (Orgs.). Antropologia e ética: o debate atual no Brasil. Niterói: EdUFF, 2004. Disponível em: http://www.abant.org.br/conteudo/livros/AntropologiaEtica.pdf. Aceso em: 12 out. 2018.

ESTATUTO DE REFORMULAÇÃO DA ACONERUQ (Associação das Comunidades Negras Rurais Quilombolas), 2007. 
FABIANI, A. O quilombo antigo e o quilombo contemporâneo: verdades e construções. In: XXIV SIMPÓSIO NACIONAL DE HISTÓRIA. 2007, São Leopoldo: Anais... São Leopoldo: $\quad$ ANPUH, $2007 . \quad$ p.1-10. Disponível em: http://snh2007.anpuh.org/resources/content/anais/Adelmir\%20Fiabani.pdf. Acesso em: 12 out. 2018.

FABIANI, A. Os quilombos contemporâneos maranhenses e a luta pela terra. Estudios Historicos, n. 2, p.1-19, ago. 2009.

FRAVET-SAAD, J. Ser afetado. In: Cadernos de campos, n. 13, 2005.

FURTADO, M. L. S. Aquilombamento no Maranhão: um Rio Grande de (im)possibilidades. 313 f. Tese (Doutorado em Geografia) - Programa de PósGraduação em geografia, Universidade Estadual Paulista, Faculdade de Ciências e Tecnologia, Presidente Prudente, 2012.

GODÓI, E. P. Territorialidade. In: SANSONE, L.; FURTADO, C. (Org.) Dicionário crítico das ciências sociais dos países de fala oficial portuguesa. Salvador, UFBA, 2014.

GEERTZ, C. A interpretação das culturas. Rio de Janeiro: LTC, 2008.

GOLDMAN, M. Alteridade e experiência: antropologia e teoria etnográfica. In: Etnográfica, Lisboa, v.10, n.1, p.161-173, maio. 2006. Disponível em: http://www.scielo.mec.pt/pdf/etn/v10n1/v10n1a08.pdf. Acesso em: 12 out. 2018.

PROJETO VIDA DE NEGRO. Vida de negro no Maranhão: uma experiência de luta, organização e resistência nos territórios quilombolas. Coleção Negro Cosme, v. 4. São Luís: SMDH, CNN-MA, PVN, 2005.

SCOTT, J. C. A dominação e a arte de resistência: discursos ocultos. Portugal: Letra Livre, 2013.

SOUSA, I. T. S. Movimentos sociais e poder: um esboço sobre a emergência do movimento negro no Maranhão. 65 f. Trabalho de conclusão de curso (Graduação em Ciências Sociais) - Curso de Ciências Sociais, Universidade Estadual do Maranhão, São-Luís, Maranhão, 2013. 